\title{
Metabolite profile comparison of a graft chimera 'Hongrou Huyou' (Citrus changshan-huyou + Citrus unshiu) and its two donor plants
}

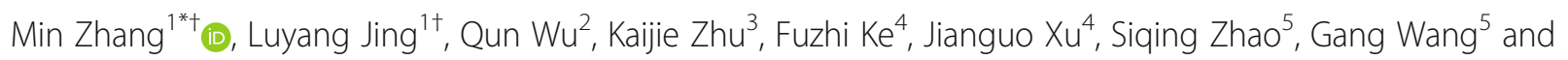
Chi Zhang ${ }^{1 *}$

\begin{abstract}
Background: Chimeras synthesized artificially by grafting are crucial to the breeding of perennial woody plants. 'Hongrou Huyou' (Citrus changshan-huyou + Citrus unshiu) is a new graft chimera originating from the junction where a Citrus changshan-huyou (" $\mathrm{C}$ ") scion was top-grafted onto a stock Satsuma mandarin 'Owari' (C. unshiu, "O"). The chimera was named OCC because the cell layer constitutions were $O$ for Layer 1(L1) and C for $L 2$ and $L 3$. In this study, profiles of primary metabolites, volatiles and carotenoids derived from different tissues in OCC and the two donors were investigated, with the aim of determining the relationship between the layer donors and metabolites.

Results: The comparison of the metabolite profiles showed that the amount and composition of metabolites were different between the peels and the juice sacs, as well as between OCC and each of the two donors. The absence or presence of specific metabolites (such as the carotenoids violaxanthin and $\beta$-cryptoxanthin, the volatile hydrocarbon germacrene $D$, and the primary metabolites citric acid and sorbose) in each tissue was identified in the three phenotypes. According to principal component analysis (PCA), overall, the metabolites in the peel of the chimera were derived from donor $\mathrm{C}$, whereas those in the juice sac of the chimera came from donor $\mathrm{O}$.

Conclusion: The profiles of primary metabolites, volatiles and carotenoids derived from the peels and juice sacs of OCC and the two donors were systematically compared. The content and composition of metabolites were different between the tissues and between OCC and the each of the two donors. A clear donor dominant pattern of metabolite inheritance was observed in the different tissues of OCC and was basically consistent with the layer origin; the peel of the chimera was derived from $C$, and the juice sacs of the chimera came from $O$. These profiles provide potential chemical markers for genotype differentiation, citrus breeding assessment, and donor selection during artificial chimera synthesis.
\end{abstract}

Keywords: Citrus, Periclinal chimera, Metabolites, Volatiles, Carotenoids

\footnotetext{
* Correspondence: mzhang@zafu.edu.cn; zhangchi1978@zafu.edu.cn

${ }^{\dagger}$ Min Zhang and Luyang Jing contributed equally to this work.

${ }^{1}$ State Key Laboratory of Subtropical Silviculture, Zhejiang A\& F University,

Hangzhou 311300, China

Full list of author information is available at the end of the article
}

(c) The Author(s). 2019 Open Access This article is distributed under the terms of the Creative Commons Attribution 4.0 International License (http://creativecommons.org/licenses/by/4.0/), which permits unrestricted use, distribution, and reproduction in any medium, provided you give appropriate credit to the original author(s) and the source, provide a link to the Creative Commons license, and indicate if changes were made. The Creative Commons Public Domain Dedication waiver (http://creativecommons.org/publicdomain/zero/1.0/) applies to the data made available in this article, unless otherwise stated. 


\section{Background}

Plant chimeras are plants composed of cells with more than two genotypes. According to the theory of 'Tunica-Corpus', the shoot apical meristem (SAM) of dicotyledonous plants is composed of three cell layers, namely, L1, L2 and L3, from the outermost layer [1]. In citrus fruits, the juice sacs and epidermal pericarps are derived from L1; the color and aroma of the fruit rind, seeds and segment walls are developed from L2; vascular bundles are produced by L3; and fruit shape is determined by L2 and/or L3 [2]. To date, there have been some reports on the discovery and identification of citrus chimeras. Zhou et al. found that the interaction between cells derived from different genotypes caused DNA mutation in the periclinal chimera fruits NFF (L1-L2-L3 = N-F-F) and FNN [2]. Wu et al. found that the fruit characteristics of the chimera Ekuliku were inconsistent with the source donor and that cross-sectional structure of the blade of the chimera was quite different from that of the two donors [3]. Zhang and his colleagues investigated two citrus chimeras named 'Zaohong' navel orange [4] and 'Hongrou Taoye' orange [5]; both two chimeras were produced from the donors sweet orange (Citrus sinensis) and Satsuma mandarin. The stomatal density and the flesh aroma of the chimera fruits in their studies were not consistent with those of the source donor; the chimera fruits showed combined characteristics of both donors [4, 5]. Since these variations in morphology and DNA mutation level occurred in plant chimeras, the accumulation patterns of metabolites in tissues and/or the cell interactions in chimeras warrant further study.

Citrus fruits are highly valued for their nutrient components, and many studies have investigated the metabolites in oranges (C. sinensis), mandarins (C. reticulata), pummelos (C. grandis) and grapefruits (C. paradisi) [6-9]. Primary metabolites, such as sugars and organic acids, are a diverse class of organic compounds that are essential for plant growth and internal quality [10]. For example, a high content of citric acid coinciding with a high level of free amino acids (especially proline) may be a reason that the shelf life of lemon is longer than that of other citrus [11]. Volatiles include several important secondary metabolites and have received extensive attention due to their marked health-promoting effects and high commodity value. $d$-Limonene is a dominant volatile in citrus and specifically protects against breast and rectal cancer [12]. Linalool and linalyl acetate have been used as anti-inflammatory agents [13], and rearrangements of germacrene D eventually produced some natural compounds [14]. Carotenoids are complex and abundant molecules in citrus fruits [15]. Some carotenoids containing $\beta$-ring moieties are precursors of vitamin $\mathrm{A}$, which are highly beneficial to chronic disease and cancer prevention [16]. Carotenoid biosynthesis and regulation in citrus fruits have been extensively studied [17-19], and these reported were helpful for our analysis of carotenoid expression in chimeras.

Graft chimeras are derived from an adventitious shoot at the graft junction and comprised of two distinct genotypes or different species [20-23]. A new graft chimera, 'Hongrou Huyou' (Citrus changshan-huyou + C. unshiu) was originated from the junction of the scion 'Changshan Huyou' ( $C$. changshan-huyou, abbreviated " $C$ ") and the stock 'Owari' Satsuma mandarin (C. unshiu, abbreviated "O"). This chimera remained yellow-skinned, similar to $\mathrm{C}$, but gained the dark orange juice sacs observed in $\mathrm{O}$ (Table 1, Fig. 1). Additionally, the chimera combined the specific DNA bands of the two donors in the nuclear, chloroplast and mitochondrial genomes through simple sequence repeat (SSR) amplification. Therefore, the chimera was assumed to be OCC because L1 was derived from $\mathrm{O}$, while L2/ L3 were derived from $\mathrm{C}$ (data not shown).

In this study, the profiles of primary metabolites, volatiles and carotenoids at the maturation period were investigated in the peels and juice sacs of the chimera and the two donors, and the correlation of metabolite accumulation between the chimera and each donor plant was analyzed to reveal the contributions of the donor plants to the different layers.

\section{Results}

Primary metabolites in OCC and its donors

As shown in Table 2, twenty-one primary metabolites were identified in peels. Based on statistical analysis, the peels of OCC (OCP) shared more similarities with the peels of $\mathrm{C}(\mathrm{CP})$ than the peels of $\mathrm{O}(\mathrm{OP})$ in these profiles. Among them, 4-aminobutanoic acid, shikimic acid and palmitic acid were exclusively detected in OCP and $\mathrm{CP}$, suggesting that these 3 compounds in OCP were only produced by $\mathrm{CP}$. In contrast, sorbose was specific to OP, with no detectable levels in OCP and CP. Both OCP and CP possess higher concentrations of acids and lower contents of total sugars; however, OCP contains middle contents of alcohols. Overall, the total metabolite

Table 1 The cultivars used in this study and their morphological traits

\begin{tabular}{llllll}
\hline No. & Cultivars & Scientific name & Abbreviation & Peel color & Juice sac color \\
\hline 1 & 'Owari' satsuma mandarin & C. unshiu & O & Orange & Dark orange \\
2 & 'Hongrou Huyou' & C. unshiu +C. changshan-huyou & OCC & Yellow & Dark orange \\
3 & 'Changshan Huyou' & C. changshan-huyou & C & Yellow & Light yellow \\
\hline
\end{tabular}

Note: Peel color and juice sac color were taken in fully mature period (collection period December 2017), see Fig. 1 for details 

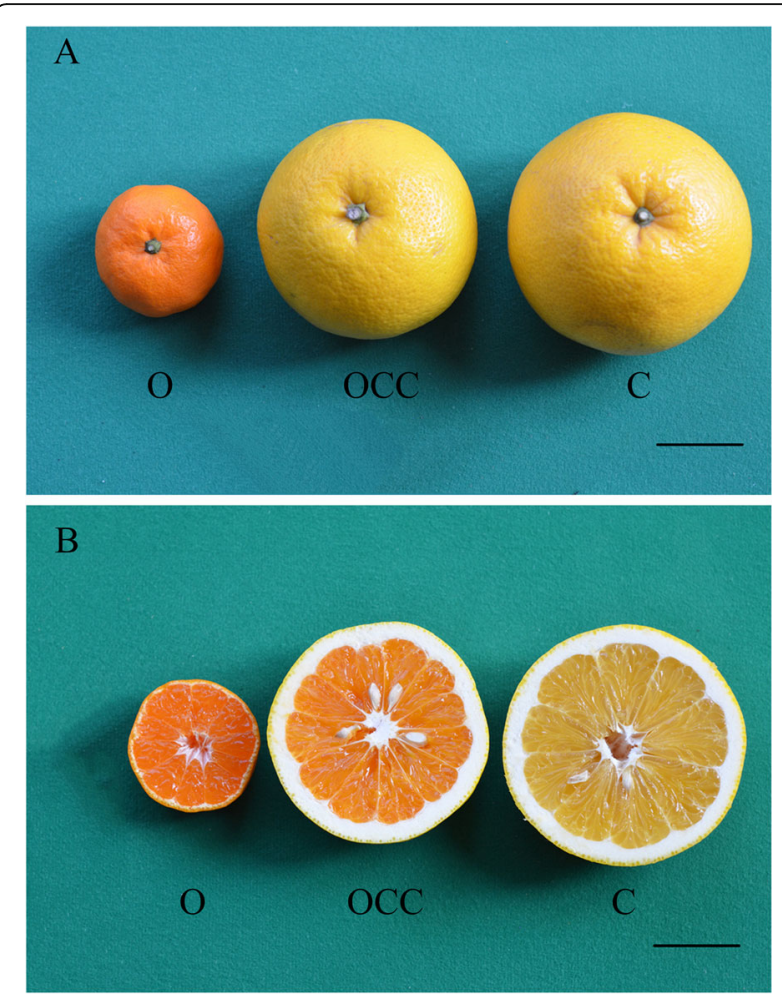

Fig. 1 Fruit morphology of 'Hongrou Huyou' (OCC) and its donor plants were harvested at the full ripening stageExternal appearance (A) and transverse section appearance (B) of 'Owari' satsuma mandarin (O), OCC (the chimera) and 'Changshan Huyou' (C), from left to right, are shown. The bars of the external and transverse sections are both $5.0 \mathrm{~cm}$.

content present in OCP was significantly lower than that in either of the donors.

Notably, some particular chemical characteristics were observed in OCP. Among acid profiles of the three samples, the level of carbamic acid was the highest in OCP; but the contents of sugar compositions (except of fucose, fructose and turanose) were the lowest in OCP.

Eighteen primary substances, listed in Table 3, were detected among the juice sacs of $\mathrm{O}(\mathrm{OJ}), \mathrm{OC}(\mathrm{OCJ})$ and $\mathrm{C}(\mathrm{CJ})$. In the present study, no significant differences were found in the total primary metabolites between $\mathrm{OCJ}$ and the juice sacs of the two donors. Interestingly, 5 metabolites (quininic acid, xylose, arabinose, turanose and scyllo-inositol) were significantly different in OCJ and in the juice sacs of the two donors. Among the three cultivars, the levels of arabinose and quininic acid in OCJ were the highest and the lowest, respectively. The remaining 3 metabolites in OCJ were significantly different from those in the two donors. In addition, 8 metabolite profiles in OCJ were consistent with one or two of the donors. However, these profiles actually showed more similarities with $\mathrm{O}$; for example, 4-aminobutanoic acid, palmitic acid and allose were present in both OCJ and OJ but were not present in CJ. Conversely, sorbose was only present in $\mathrm{CJ}$ and was undetectable in $\mathrm{OCJ}$ and $\mathrm{OJ}$.

Interestingly, 3 compounds showed some hereditary differences in OCJ (oxalic acid, sorbose and rhamnose). Among them, oxalic acid and rhamnose were undetectable only in OCJ, which caused obvious discrepancies between OCC and its donors. However, sorbose was undetectable in both OCJ and its layer source donor $\mathrm{O}$.

\section{Volatile compositions of OCC and its donors}

With regard to the volatiles in the peels of the three cultivars, 36 substances are listed in Table 4, including monoterpenes, sesquiterpenes, alcohols, aldehydes, phenols and others. The monoterpenes were the most abundant profiles quantified; $d$-limonene was the dominant compound, accounting for $88.65,81.23$ and $80.77 \%$ of the total volatiles in $\mathrm{OP}, \mathrm{OCP}$ and $\mathrm{CP}$, respectively. After $d$-limonene, the main common compounds in the three cultivars were $\gamma$-terpinene, $\beta$-myrcene and $\alpha$-pinene.

The results showed that OCP had a stronger correlation with $\mathrm{CP}$ than with OP. First, according to the statistical analysis, 25 volatiles were not significantly different between OCP and CP, but only 16 volatiles were not significantly different between OCP and OP. This finding indicated that $\mathrm{CP}$ had the dominant position in the regulation of the chemical profiles in OCP and that more chemical traits in OCP were inherited from CP than from OP. Second, the main volatiles in OCP were completely consistent with those in $\mathrm{CP}$, including $d$-limonene, $\gamma$-terpinene, germacrene $\mathrm{D}, \beta$-myrcene and $\alpha$-pinene (sorted from high to low concentrations), but the relative concentrations of the main volatiles in OP were divergent ( $d$-limonene, $\gamma$-terpinene, $\beta$ myrcene, $\alpha$-pinene, $\beta$-elemene). This was mainly because the content of germacrene $\mathrm{D}$ was significantly higher in $\mathrm{OCP}$ and $\mathrm{CP}$ than in $\mathrm{OP}$, strongly suggesting that germacrene D mainly originated from $\mathrm{CP}$ and that $\mathrm{OP}$ had less impact on the development of OCP. Third, it is worth noting that 2,4-di-t-butylphenol was truly unique and was only undetected in OP; but possessed by both OCC and C.

In addition, most of the volatiles in OCP were either inclined to one donor or maintained some degree between the two donors. However, only $(E)$-3-hexen-1-ol and 3-hexenal were significantly increased in OCP compared with the two donors.

In the edible juice sacs, up to 19 volatile compounds were detected (Table 5). OCJ was highly correlated with $\mathrm{OJ}$ in total volatiles and monoterpenes (the leading volatiles), especially in dominant substances; the concentration of $d$-limonene in $\mathrm{OJ}$ and $\mathrm{OCJ}$ was significantly higher than that in CJ, representing 78.07 and $72.64 \%$ of the total volatiles in $\mathrm{OJ}$ and OCJ, respectively, but only $60.03 \%$ of that in CJ. In addition to $d$-limonene, significant similarities in methyl nonanoate, copaene, and octanal were also observed between 
Table 2 Primary metabolite profiles ( $\mu \mathrm{g}$ g-1 FW) in the peels of OCC and its donor plants

\begin{tabular}{|c|c|c|c|c|}
\hline No. & Primary metabolites $\left(\mu \mathrm{g} \mathrm{g}^{-1}\right)$ & $\mathrm{OP}$ & OCP & $\mathrm{CP}$ \\
\hline \multicolumn{5}{|c|}{ Organic acids } \\
\hline 1 & Carbamic acid & $8.23 \pm 0.45 c$ & $205.82 \pm 14.44 a$ & $173.78 \pm 9.83 b$ \\
\hline 2 & Cyclohexaneacetic acid & $0.56 \pm 0.09 c$ & $2.28 \pm 0.41 b$ & $3.35 \pm 0.32 a$ \\
\hline 3 & Malic acid & $92.87 \pm 9.42 c$ & $211.84 \pm 8.73 b$ & $280.92 \pm 12.48 a$ \\
\hline 4 & Quininic acid & $273.14 \pm 11.78 b$ & $341.09 \pm 25.51 \mathrm{a}$ & $354.57 \pm 47.87 a$ \\
\hline 5 & 2-Ketoglutaric acid & $64.77 \pm 6.22 \mathrm{a}$ & $35.08 \pm 2.73 b$ & $41.24 \pm 3.70 b$ \\
\hline 6 & 4-Aminobutanoic acid & nd & $42.49 \pm 3.71 a$ & $24.26 \pm 7.77 b$ \\
\hline 7 & Shikimic acid & nd & $11.21 \pm 1.44 a$ & $11.16 \pm 1.06 a$ \\
\hline \multirow[t]{2}{*}{8} & Palmitic acid & nd & $29.14 \pm 2.07 a$ & $31.97 \pm 1.54 a$ \\
\hline & Sum & $439.57 \pm 27.97 b$ & $878.94 \pm 59.03 a$ & $921.27 \pm 84.57 a$ \\
\hline \multicolumn{5}{|c|}{ Sugars } \\
\hline 9 & Xylose & $215.09 \pm 3.73 a$ & $79.35 \pm 6.14 c$ & $112.00 \pm 5.65 b$ \\
\hline 10 & Mannose & $24,997.79 \pm 1538.92 \mathrm{a}$ & $11,139.04 \pm 654.61 \mathrm{c}$ & $14,008.21 \pm 659.76 b$ \\
\hline 11 & Galactose & $6961.91 \pm 512.69 a$ & $2910.33 \pm 191.21 \mathrm{C}$ & $3885.98 \pm 176.32 b$ \\
\hline 12 & Fucose & $5.83 \pm 0.60 c$ & $12.82 \pm 1.55 a$ & $9.50 \pm 0.92 b$ \\
\hline 13 & Fructose & $20,950.50 \pm 1276.05 a$ & $9533.23 \pm 501.14 b$ & $10,982.41 \pm 464.13 b$ \\
\hline 14 & $d$-Psicose & $246.44 \pm 11.15 a$ & $47.54 \pm 9.82 c$ & $88.83 \pm 6.39 b$ \\
\hline 15 & Turanose & $91.76 \pm 9.73 a$ & $25.64 \pm 2.07 b$ & $33.00 \pm 2.89 b$ \\
\hline 16 & Sucrose & $16,576.74 \pm 471.54 a$ & $7352.21 \pm 162.93 \mathrm{c}$ & $8777.85 \pm 359.66 b$ \\
\hline 17 & Myo-Inositol & $1102.16 \pm 76.96 a$ & $1035.31 \pm 59.25 \mathrm{ab}$ & $965.58 \pm 39.84 b$ \\
\hline \multirow[t]{2}{*}{18} & Sorbose & $160.32 \pm 4.82 \mathrm{a}$ & nd & nd \\
\hline & Sum & $71,308.53 \pm 3906.19 a$ & $32,135.47 \pm 1588.70 b$ & $38,863.34 \pm 1715.57 b$ \\
\hline \multicolumn{5}{|c|}{ Alcohols } \\
\hline 19 & Glycerol & $125.80 \pm 13.79 c$ & $247.62 \pm 32.8 b$ & $303.96 \pm 32.17 a$ \\
\hline \multirow[t]{3}{*}{20} & Scyllo-Inositol & $54.75 \pm 4.92 c$ & $169.21 \pm 4.08 b$ & $291.89 \pm 14.46 a$ \\
\hline & Sum & $180.56 \pm 18.72 c$ & $416.84 \pm 36.89 b$ & $595.85 \pm 46.63 a$ \\
\hline & Total & $71,928.66 \pm 3952.88 a$ & $33,431.25 \pm 1684.62 \mathrm{C}$ & $40,380.46 \pm 1645.96 b$ \\
\hline
\end{tabular}

OJ and OCJ, and we hypothesized that all these compounds in $\mathrm{OCJ}$ originated from $\mathrm{O}$ to a great extent.

Moreover, typical volatile metabolites were observed in OCJ. For example, nootkatone and pentadecanal were present at the largest amounts in OCJ. In contrast, $\gamma$-terpinene was significantly lower in OCJ than in either of the donors. Furthermore, we were particularly interested in $\alpha$-ylangene, which was only detected in OCJ but not in the two donors, and this volatile has rarely been reported in any citrus species.

\section{Carotenoid constituents of OCC and its donors}

As shown in Table 6, a total of 9 carotenoids were detected in OCC and the two donors. Generally, the contents and types of carotenoids in OCC were very similar to that in $C$ in the peels, while they were intermediate between the donors in the juice sacs.
Notably, donor $\mathrm{O}$ had the highest contents of all carotenoid components in both the peels and juice sacs among the three genotypes. The carotenoids, except violaxanthin, lutein and phytofluene, in OCP were all significantly consistent with $\mathrm{CP}$. The carotenoids in OCJ were an intermediate between those in the two donors except of violaxanthin, luteoxanthin and lutein. In fact, all of the carotenoids detected in OJ and OCJ were particularly higher than those detected in CJ. It is remarkable that $\alpha$-carotene accumulated much less than other carotenoids both in the peels and juice sacs.

The dominant components in the peels and juice sacs of OCC and the two donors were different. Violaxanthin was the primary component in the peels, and $\beta$-cryptoxanthin was dominant in the juice sacs. The main carotenoids in OCJ, such as $\beta$-cryptoxanthin, phytoene and phytofluene, changed much more than those in OCP, which maintained the flesh color of OCC similar with layer donor O. 
Table 3 Primary metabolite profiles $\left(\mathrm{\mu g} \mathrm{g}^{-1} \mathrm{FW}\right)$ in the juice sacs of OCC and its donor plants

\begin{tabular}{|c|c|c|c|c|}
\hline No. & Primary metabolites $\left(\mu \mathrm{g} \mathrm{g}^{-1}\right)$ & OJ & OCJ & CJ \\
\hline \multicolumn{5}{|c|}{ Organic acids } \\
\hline 1 & Oxalic acid & $22.67 \pm 0.90 \mathrm{a}$ & nd & $19.16 \pm 3.99 a$ \\
\hline 2 & Malic acid & $206.33 \pm 21.44 b$ & $172.40 \pm 8.68 b$ & $363.95 \pm 60.83 a$ \\
\hline 3 & 4-Aminobutanoic acid & $10.36 \pm 1.00 b$ & $16.01 \pm 4.16 a$ & nd \\
\hline 4 & Citric acid & $1131.33 \pm 9.58 a b$ & $1213.74 \pm 59.98 a$ & $965.81 \pm 166.44 b$ \\
\hline 5 & Quininic acid & $37.49 \pm 4.79 b$ & $22.24 \pm 1.77 c$ & $50.68 \pm 3.64 a$ \\
\hline \multirow[t]{2}{*}{6} & Palmitic acid & $38.62 \pm 2.57 a$ & $20.23 \pm 0.16 b$ & nd \\
\hline & Sum & $1446.81 \pm 40.28 a$ & $1444.61 \pm 48.07 a$ & $1399.60 \pm 227.91 a$ \\
\hline \multicolumn{5}{|c|}{ Sugars } \\
\hline 7 & Xylose & $57.18 \pm 0.58 a$ & $16.76 \pm 1.28 b$ & $4.47 \pm 0.77 c$ \\
\hline 8 & Arabinose & $5.39 \pm 0.10 b$ & $15.11 \pm 0.81 a$ & $2.36 \pm 0.39 c$ \\
\hline 9 & Fructose & $14,259.18 \pm 237.19 a$ & $12,389.95 \pm 1357.50 b$ & $11,731.42 \pm 622.19 b$ \\
\hline 10 & Mannose & $155.25 \pm 17.50 \mathrm{a}$ & $139.88 \pm 11.24 a$ & $162.82 \pm 27.27 a$ \\
\hline 11 & Sorbose & nd & nd & $54.88 \pm 1.50 a$ \\
\hline 12 & Glucose 2,3,4,5,6-pentakis-O-(trimethylsilyl)-, o-methyloxyme, (1Z)- & $17,227.71 \pm 687.96 a$ & $17,073.88 \pm 1494.37 a$ & $15,731.50 \pm 1048.49 a$ \\
\hline 13 & Rhamnose & $17.51 \pm 1.60 \mathrm{a}$ & nd & $10.55 \pm 0.87 b$ \\
\hline 13 & Myo-Inositol & $1508.79 \pm 45.70 a$ & $1503.50 \pm 31.59 a$ & $240.54 \pm 9.76 b$ \\
\hline 14 & Allose & $2.69 \pm 0.26 a$ & $2.10 \pm 0.28 b$ & nd \\
\hline 15 & Sucrose & $21,362.29 \pm 1880.50 a$ & $21,537.81 \pm 1705.67 a$ & $22,017.88 \pm 849.67 a$ \\
\hline 16 & Turanose & $223.49 \pm 34.64 a$ & $160.54 \pm 14.71 b$ & $17.18 \pm 2.04 \mathrm{C}$ \\
\hline 17 & Sum & $54,819.49 \pm 2906 a$ & $52,839.53 \pm 3493.60 a$ & $49,973.6 \pm 2478.50 a$ \\
\hline \multicolumn{5}{|c|}{ Alcohol } \\
\hline \multirow[t]{2}{*}{18} & Scyllo-Inositol & $64.63 \pm 3.99 c$ & $116.81 \pm 1.38 b$ & $190.91 \pm 9.79 a$ \\
\hline & Total & $56,330.92 \pm 2950 a$ & $54,400.95 \pm 3463.03 a$ & $51,564.11 \pm 2695.72 a$ \\
\hline
\end{tabular}

The correlation of the total carotenoids in OCC and in each of the two donors was analyzed to determine the source of tissue coloration. It was suggested that the carotenoid accumulation in OCC had an obvious donor bias and was different in the peels and juice sacs (Table 7). In the peels, the total carotenoids in OCC were significantly correlated with those in $\mathrm{C}$ and $\mathrm{O}$. In the juice sacs, only the correlation coefficient between OCC and donor O was statistically significant (0.957). This donor bias in the carotenoids in the peel and juice sac of mature OCC can partly explain why the peel of OCC is light yellow, similar to donor $C$, whereas the juice sac is dark orange, similar to donor $\mathrm{O}$.

PCA analysis of metabolites in the peels and juice sacs of OCC and the two donors

In terms of the three categories of metabolites, principal component analysis (PCA) was performed to compare the different tissues in OCC and the two donors.

In the $\mathrm{PC} 1$ direction of the score map, there was a clear distinction between donor $\mathrm{O}$ and the other genotypes (OCC and donor C) in primary metabolites (Fig. 2A-1), volatiles (Fig. 2A-2) and carotenoids (Fig. 2A-3), according to the peels.

In the juice sacs, donor $\mathrm{C}$ was clearly distinguished from $\mathrm{OCC}$ and donor $\mathrm{O}$ in the primary metabolites (Fig. 2B-1), volatiles (Fig. 2B-2) and carotenoids (Fig. 2B-3), according to the PC1 direction of the score map. However, OCJ was separated from OJ in PC1 (Fig. 2B-3), indicating a novel profile of the carotenoid accumulation pattern in the chimera.

\section{Discussion}

Studies focused on phenotypes, fruit qualities and genome compositions [2-5] have contributed to the knowledge of chimeric plants; however, the mechanism of metabolite accumulation in genetically different cells remains unknown. In this work, the profiles of primary metabolites and secondary metabolites were systematically compared in a novel citrus chimera, OCC, and its donor plants, which may provide valuable insight into the genetic contributions and inheritance patterns from grafting donors to chimeras. 
Table 4 Volatiles profiles ( $\mu \mathrm{g} \mathrm{g}^{-1} \mathrm{FW}$ ) in the peels of OCC and its donor plants

\begin{tabular}{|c|c|c|c|c|}
\hline No. & Volatiles $\left(\mu \mathrm{g} \mathrm{g}^{-1}\right)$ & OP & OCP & $C P$ \\
\hline \multicolumn{5}{|c|}{ Monoterpene } \\
\hline 1 & $a$-Thujene & $144.35 \pm 27.72 b$ & $207.23 \pm 30.8 a$ & $264.98 \pm 30.08 a$ \\
\hline 2 & a-Pinene & $804.57 \pm 153.03 b$ & $842.83 \pm 125.46 a b$ & $1089.03 \pm 117.82 a$ \\
\hline 3 & Sabinene & $128.77 \pm 24.57 a$ & $140.56 \pm 22.06 a$ & $173.87 \pm 18.41 a$ \\
\hline 4 & $\beta$-Pinene & $236.92 \pm 45.00 \mathrm{~b}$ & $429.98 \pm 66.59 a$ & $521.91 \pm 59.04 a$ \\
\hline 5 & $\beta$-Myrcene & $1262.26 \pm 244.69 a$ & $1204.28 \pm 188.37 a$ & $1506.58 \pm 172.6 a$ \\
\hline 6 & a-Phellandrene & $33.08 \pm 7.50 c$ & $55.34 \pm 6.54 b$ & $70.20 \pm 5.31 a$ \\
\hline 7 & a-Terpinene & $73.05 \pm 13.42 b$ & $118.21 \pm 17.05 a$ & $143.5 \pm 15.66 a$ \\
\hline 8 & $d$-limonene & $60,800.80 \pm 7185.92 \mathrm{a}$ & $59,857.96 \pm 5806.31 a$ & $66,345.79 \pm 5599.97 a$ \\
\hline 9 & $\beta$-cis-Ocimene & $46.03 \pm 8.01$ & $49.36 \pm 8.11 b$ & $68.38 \pm 7.56 a$ \\
\hline 10 & $\gamma$-Terpinene & $3213.21 \pm 583.21 b$ & $5430.11 \pm 835.11 a$ & $6360.18 \pm 679.34 a$ \\
\hline 11 & Terpinolene & $149.98 \pm 29.22 b$ & $246.07 \pm 38.77 a$ & $286.81 \pm 31.14 a$ \\
\hline \multicolumn{5}{|c|}{ Monoterpene alcohols } \\
\hline 12 & Linalool & $152.41 \pm 22.04 a$ & $55.37 \pm 5.15 b$ & $54.97 \pm 5.28 b$ \\
\hline 13 & $a$-Terpineol & $76.01 \pm 7.88 \mathrm{a}$ & $64.6 \pm 5.69 a$ & $40.38 \pm 31.29 a$ \\
\hline \multicolumn{5}{|c|}{ Monoterpene aldehydes } \\
\hline 14 & Citronellal & $28.25 \pm 5.06 a$ & $19.82 \pm 3.2 b$ & $19.28 \pm 1.00 \mathrm{~b}$ \\
\hline \multicolumn{5}{|c|}{ Monoterpene esters } \\
\hline 15 & Methyl 2-methyloctanoate & $227.59 \pm 0.78 a$ & $225.77 \pm 2.46 a$ & $228.57 \pm 0.64 a$ \\
\hline 16 & Citronellol acetate & $5.56 \pm 0.46 b$ & $16.83 \pm 3.03 a$ & $15.44 \pm 1.75 a$ \\
\hline \multirow[t]{2}{*}{17} & (R)-lavandulyl acetate & $16.55 \pm 3.36 c$ & $68.04 \pm 10.32 b$ & $98.38 \pm 11.36 a$ \\
\hline & Sum & $67,399.39 \pm 8348.50 a$ & $69,032.36 \pm 7166.67 a$ & $77,288.24 \pm 6729.2 a$ \\
\hline \multicolumn{5}{|c|}{ Sesquiterpene } \\
\hline 18 & Copaene & $44.00 \pm 8.93 b$ & $60.57 \pm 10.44 a b$ & $68.01 \pm 7.69 a$ \\
\hline 19 & $\beta$-Cubebene & $35.07 \pm 7.50 \mathrm{~b}$ & $45.92 \pm 7.44 a b$ & $52.66 \pm 5.54 a$ \\
\hline 20 & $\beta$-Elemene & $21.77 \pm 3.73 a$ & $18.42 \pm 3.55 a$ & $25.39 \pm 3.63 a$ \\
\hline 21 & Caryophyllene & $22.68 \pm 3.81 b$ & $58.03 \pm 9.62 a$ & $68.36 \pm 7.67 a$ \\
\hline 22 & (E)- $\beta$-Famesene & $37.4 \pm 7.50 \mathrm{~b}$ & $117.74 \pm 23.03 a$ & $128.65 \pm 12.12 \mathrm{a}$ \\
\hline 23 & Germacrene D & $123.72 \pm 26.64 b$ & $2772.96 \pm 488.7 a$ & $2525.56 \pm 267.24 a$ \\
\hline 24 & $\gamma$-Elemene & $17.19 \pm 2.72 b$ & $196.80 \pm 35.29 a$ & $174.66 \pm 18.57 \mathrm{a}$ \\
\hline 25 & $(-)$ - $\beta$-Elemene & $440.45 \pm 93.78 a$ & $138.93 \pm 24.83 b$ & $171.49 \pm 19.39 b$ \\
\hline 26 & $\delta$-Cadinene & $57.02 \pm 12.36 a$ & $69.14 \pm 12.49 a$ & $79.21 \pm 9.92 a$ \\
\hline 27 & $\delta$-Elemene & $33.08 \pm 6.31 c$ & $155.35 \pm 26.62 b$ & $195.32 \pm 19.83 \mathrm{a}$ \\
\hline \multicolumn{5}{|c|}{ Sesquiterpene alcohols } \\
\hline \multirow[t]{2}{*}{28} & Nootkatone & $2.79 \pm 0.96 c$ & $28.59 \pm 3.67 b$ & $67.88 \pm 4.92 a$ \\
\hline & Sum & $835.19 \pm 172.72 b$ & $3662.44 \pm 645.18 a$ & $3557.22 \pm 375.92 a$ \\
\hline \multicolumn{5}{|c|}{ Alcohol } \\
\hline 29 & (E)-3-Hexen-1-ol & $8.30 \pm 1.13 c$ & $34.14 \pm 2.09 a$ & $15.79 \pm 3.19 b$ \\
\hline \multicolumn{5}{|c|}{ Aldehydes } \\
\hline 30 & 3-Hexenal & $51.52 \pm 4.72 c$ & $72.66 \pm 1.12 \mathrm{a}$ & $64.51 \pm 3.14 b$ \\
\hline 31 & Hexanal & $25.21 \pm 2.49 a$ & $25.38 \pm 0.26 a$ & $18.56 \pm 1.05 b$ \\
\hline 32 & (E)-2-Hexenal & $5.49 \pm 1.13 a b$ & $7.48 \pm 1.5 \mathrm{a}$ & $4.41 \pm 1.09 b$ \\
\hline \multirow[t]{2}{*}{33} & Decanal & $72.59 \pm 13.82 \mathrm{a}$ & $80.43 \pm 15.23 a$ & $99.15 \pm 10.55 a$ \\
\hline & Sum & $163.11 \pm 20.83 a$ & $220.10 \pm 16.89 a$ & $202.42 \pm 18.21 a$ \\
\hline
\end{tabular}


Table 4 Volatiles profiles $\left(\mu \mathrm{g} \mathrm{g}^{-1} \mathrm{FW}\right.$ ) in the peels of OCC and its donor plants (Continued)

\begin{tabular}{|c|c|c|c|c|}
\hline No. & Volatiles $\left(\mu \mathrm{g} \mathrm{g}^{-1}\right)$ & OP & OCP & $\mathrm{CP}$ \\
\hline \multicolumn{5}{|c|}{ Phenol } \\
\hline 34 & 2,4-di-t-butylphenol & nd & $42.13 \pm 6.79 a$ & $37.71 \pm 8.4 a$ \\
\hline \multicolumn{5}{|c|}{ Others } \\
\hline 35 & o-Cymene & $103.06 \pm 19.73 b$ & $91.13 \pm 12.45 b$ & $156.95 \pm 18.41 a$ \\
\hline \multirow[t]{3}{*}{36} & n-Hexadecanoic acid & $58.71 \pm 15.95 b$ & $115.47 \pm 39.42 b$ & $207.42 \pm 33.32 a$ \\
\hline & Sum & $161.77 \pm 20.18 b$ & $248.722 \pm 58.28 b$ & $402.08 \pm 48.20 \mathrm{a}$ \\
\hline & Total & $68,559.46 \pm 8553.26 a$ & $73,163.61 \pm 7884.82 a$ & $81,449.95 \pm 7136.32 a$ \\
\hline
\end{tabular}

Table 5 Volatiles profiles ( $\mu \mathrm{g} \mathrm{g}^{-1} \mathrm{FW}$ ) in juice sacs of OCC and its donor plants

\begin{tabular}{|c|c|c|c|c|}
\hline No. & Volatiles $\left(\mu \mathrm{g} \mathrm{g}^{-1}\right)$ & OJ & OCJ & CJ \\
\hline \multicolumn{5}{|c|}{ Monoterpene } \\
\hline 1 & Linalool & $46.22 \pm 2.08 a$ & $33.91 \pm 1.31 b$ & $20.53 \pm 2.07 c$ \\
\hline 2 & $y$-Terpinene & $20.90 \pm 0.94 b$ & $16.01 \pm 1.74 \mathrm{C}$ & $28.08 \pm 3.62 \mathrm{a}$ \\
\hline 3 & $d$-Limonene & $383.05 \pm 32.38 a$ & $402.18 \pm 24.76 a$ & $298.7 \pm 10.03 b$ \\
\hline 4 & $\beta$-Myrcene & $44.59 \pm 0.86 a$ & $36.43 \pm 2.91 b$ & $29.54 \pm 3.83 c$ \\
\hline 5 & $\beta$-Elemene & $1.96 \pm 0.16 c$ & $2.48 \pm 0.08 b$ & $3.09 \pm 0.42 \mathrm{a}$ \\
\hline \multicolumn{5}{|c|}{ Monoterpene esters } \\
\hline 6 & Methyl 2-methyloctanoate & $11.01 \pm 0.55 b$ & $18.12 \pm 0.56 a$ & $1.80 \pm 0.04 c$ \\
\hline \multirow[t]{2}{*}{7} & Methyl nonanoate & $1.85 \pm 0.05 b$ & $1.87 \pm 0.04 b$ & $3.65 \pm 0.38 a$ \\
\hline & Sum & $509.57 \pm 37.02 \mathrm{a}$ & $510.99 \pm 31.39 a$ & $385.39 \pm 20.39 b$ \\
\hline \multicolumn{5}{|c|}{ Sesquiterpene } \\
\hline 8 & Germacrene D & $0.17 \pm 0.03 b$ & $2.81 \pm 0.48 \mathrm{a}$ & $0.46 \pm 0.06 b$ \\
\hline 9 & Copaene & $14.31 \pm 2.03 b$ & $19.92 \pm 2.70 b$ & $49.69 \pm 2.14 a$ \\
\hline 10 & a-ylangene & nd & $16.05 \pm 3.59 a$ & nd \\
\hline 11 & Germacrene B & $11.45 \pm 1.80 \mathrm{a}$ & $6.99 \pm 1.95 b$ & $0.74 \pm 0.19 c$ \\
\hline \multicolumn{5}{|c|}{ Sesquiterpene alcohols } \\
\hline \multirow[t]{2}{*}{12} & Nootkatone & $1.13 \pm 0.68 b$ & $3.62 \pm 1.35 a$ & $0.45 \pm 0.24 b$ \\
\hline & Sum & $27.06 \pm 4.55 c$ & $49.39 \pm 10.08 b$ & $51.34 \pm 2.64 a$ \\
\hline \multicolumn{5}{|c|}{ Aldehydes } \\
\hline 13 & Decanal & $1.47 \pm 0.08 c$ & $2.47 \pm 0.75 b$ & $3.59 \pm 0.39 a$ \\
\hline 14 & Dodecanal & $2.25 \pm 0.07 a b$ & $2.83 \pm 0.66 a$ & $1.72 \pm 0.53 b$ \\
\hline 15 & Pentadecanal & $2.28 \pm 0.16 b$ & $3.63 \pm 0.74 a$ & $2.53 \pm 0.54 b$ \\
\hline \multirow[t]{2}{*}{16} & Octanal & $1.06 \pm 0.06 a$ & $1.13 \pm 0.15 a$ & $0.69 \pm 0.21 b$ \\
\hline & Sum & $7.06 \pm 0.38 b$ & $10.06 \pm 2.31 \mathrm{a}$ & $8.53 \pm 1.67 a b$ \\
\hline \multicolumn{5}{|c|}{ Phenol } \\
\hline 17 & 2,4-di-t-Butylphenol & $3.53 \pm 0.26 b$ & $6.24 \pm 0.11 a$ & $5.42 \pm 1.54 a$ \\
\hline \multirow[t]{2}{*}{18} & n-Tridecan-1-ol & $23.51 \pm 2.13 a$ & $16.12 \pm 1.02 b$ & $12.68 \pm 2.53 b$ \\
\hline & Sum & $27.04 \pm 2.39 a$ & $22.36 \pm 1.14 a$ & $18.10 \pm 4.07 a$ \\
\hline \multicolumn{5}{|c|}{ Others } \\
\hline \multirow[t]{2}{*}{19} & n-Hexadecanoic acid & $1.39 \pm 0.14 a b$ & $0.83 \pm 0.46 b$ & $1.52 \pm 0.20 \mathrm{a}$ \\
\hline & Total & $572.12 \pm 44.48 a$ & $593.64 \pm 45.38 a$ & $464.88 \pm 28.96 b$ \\
\hline
\end{tabular}


Table 6 Carotenoid content $\left(\mu \mathrm{g} \mathrm{g}^{-1} \mathrm{DW}\right.$ ) in peel and juice sac of OCC and its donor plants

\begin{tabular}{|c|c|c|c|c|c|c|c|}
\hline No. & Carotenoid content ( $\mu \mathrm{g} \mathrm{g}-1$ ) & $\mathrm{OP}$ & OCP & $\mathrm{CP}$ & OJ & OCJ & CJ \\
\hline 1 & Violaxanthin & $941.53 \pm 42.97 a$ & $772.11 \pm 54.36 b$ & $911.83 \pm 37.03 a$ & $5.02 \pm 1.21 a$ & $5.20 \pm 1.47 a$ & $4.17 \pm 0.98 a$ \\
\hline 2 & Luteoxanthin & $67.33 \pm 8.93 a$ & $33.24 \pm 3.57 b$ & $29.94 \pm 5.62 b$ & $18.04 \pm 0.69 b$ & $21.79 \pm 0.76 a$ & $0.58 \pm 0.11 c$ \\
\hline 3 & Lutein & $110.04 \pm 8.67 a$ & $44.54 \pm 5.56 b$ & $24.98 \pm 1.27 c$ & $5.67 \pm 0.69 a$ & $4.97 \pm 0.52 a$ & $4.72 \pm 0.67 a$ \\
\hline 4 & Zeaxanthin & $61.40 \pm 5.73 a$ & $3.36 \pm 0.84 b$ & $4.63 \pm 1.21 b$ & $34.39 \pm 0.83 a$ & $19.97 \pm 2.32 b$ & $6.62 \pm 0.58 c$ \\
\hline 5 & $\beta$-cryptoxanthin & $356.81 \pm 8.04 a$ & $9.07 \pm 1.66 b$ & $14.65 \pm 0.96 b$ & $290.73 \pm 2.83 a$ & $132.74 \pm 6.43 b$ & $4.39 \pm 0.60 c$ \\
\hline 6 & a-carotene & $12.13 \pm 1.52 \mathrm{a}$ & nd & nd & $5.27 \pm 0.07 a$ & $1.46 \pm 0.03 b$ & nd \\
\hline 7 & $\beta$-carotene & $15.37 \pm 3.01 a$ & $5.19 \pm 1.23 b$ & $1.26 \pm 0.18 c$ & $14.31 \pm 1.28 a$ & $4.25 \pm 1.09 b$ & $0.22 \pm 0.11 c$ \\
\hline 8 & Phytoene & $383.58 \pm 9.23 a$ & $44.71 \pm 3.41 b$ & $71.34 \pm 6.41 b$ & $123.30 \pm 4.26 a$ & $42.01 \pm 2.21 b$ & nd \\
\hline \multirow[t]{2}{*}{9} & Phytofluene & $243.24 \pm 13.28 a$ & $26.80 \pm 3.15 c$ & $49.58 \pm 3.76 b$ & $106.59 \pm 0.57 a$ & $18.43 \pm 2.78 b$ & $2.50 \pm 0.37 c$ \\
\hline & Total & $2191.43 \pm 101.38 a$ & $939.02 \pm 73.78 b$ & $1108.21 \pm 56.44 b$ & $603.32 \pm 12.44 a$ & $251.10 \pm 17.61 b$ & $23.21 \pm 3.41 c$ \\
\hline
\end{tabular}

\section{Donor dominant metabolite analysis in OCC}

In citrus chimeras, the juice sacs develop from the L1 cell layer, and the peels are derived from the L2 cell layers $[1,2]$. In this study, the metabolites in the OCC chimera were more similar to those in $\mathrm{C}$ in the peels, but more similar to those in $\mathrm{O}$ in the juice sacs, which seemed to confirm the speculated layer origins. Carotenoids are primary nutrients in citrus, and their content and composition vary greatly among citrus varieties [24]. Several reports have focused on the differentiation of citrus genotypes through differences in carotenoid profiles. For example, thirty-two citrus fruits were clearly separated by differences in the $\beta$-cryptoxanthin content of juice [16]. Similarly, twenty-five citrus genotypes were classified on the basis of cis-violaxanthin and $\beta$-cryptoxanthin in juice [25]. Furthermore, violaxanthin and $\beta$ cryptoxanthin in the flavedo and juice sac were successfully used to differentiate among 39 citrus genotypes [26]. Herein, three groups were classified according to the amounts of specific type of carotenoids in citrus. Satsuma mandarin represents mandarin cultivars and contained abundant $\beta$-cryptoxanthin in both the flavedo and juice sac. Oranges are rich in violaxanthin in both the flavedo and juice sacs. Pummelo was separated from oranges and mandarins, as it lacks $\beta$-cryptoxanthin and violaxanthin [15]. In this study, donor $C$ was documented to be the hybrid of pummelo, orange and/or

Table 7 Correlation coefficient of carotenoid content between OCC and two donors

\begin{tabular}{llllll}
\hline Tissues & Metabolites & Cultivars & O & OCC & C \\
\hline Peel & Carotenoids & O & 1 & & \\
& & OCC & $0.892^{* *}$ & 1 & \\
& & C & $0.905^{* *}$ & $0.999^{* *}$ & 1 \\
Juice sac & Carotenoids & O & 1 & & \\
& & OCC & $0.957^{* *}$ & 1 & \\
& & C & 0.146 & 0.210 & 1 \\
\hline
\end{tabular}

other citrus species [27-29]. Notably, the primary cell lineage of $\mathrm{C}$ includes pummelo and orange, which contain low levels of $\beta$-cryptoxanthin. In this study, the level of $\beta$-cryptoxanthin in OCP was as low as that in $\mathrm{CP}$, while OCJ accumulated much more $\beta$-cryptoxanthin than did CJ. Likewise, a previous study on the citrus chimera Ekuliku revealed that its juice sac was developed from the L1 donor Nankan (C. unshiu), and the peel was developed from the L2 and L3 donor Hamlin (C. sinensis) [3]. Similarly, the leaf morphology variation of Brassica chimeras was only controlled by red cabbage and was reproducible and directional in progenies [30].

Metabolites are first biosynthesized in vivo. Three key genes (CitPds, CitZds and CitCrt) upstream of the carotenoid biosynthesis pathway were reported to be expressed at low levels in a somatic hybrid between $C$. reticulata and C. limon, which were biased towards parent lemon, resulting in low carotenoid content in the hybrid [31]. Similarly, a somatic hybrid between 'Bonnaza' naval orange $(C$. sinensis) and rough lemon (C. jambhiri) showed a similar carotenoid content to that of rough lemon, whose expression patterns of the lycopene $\varepsilon$-cyclase gene (LCYE) and the zeaxanthin epoxidase gene (ZEP) were more similar to those of rough lemon [32]. These scientists believed that the expression of carotenoid genes was not a simple additive effect between parents but rather indicated a certain amount of genomic imprinting, that is, the expression of homologous genes in polyploids biased toward one parent $[31,32]$. Herein, it was interesting that the carotenogenesis of the chimera OCC was a balanced representation of the two sets of genetically different cells. It was assumed that in the newly produced chimera OCC, the homologous genes derived from a distinct layer may be selectively expressed in the same metabolic pathway because of changes in DNA methylation that were speculated to be induced during grafting [33] and finally produce the coordinate on expression patterns in each fruit tissue to achieve the coexistence of two sets of genetically different cells. 

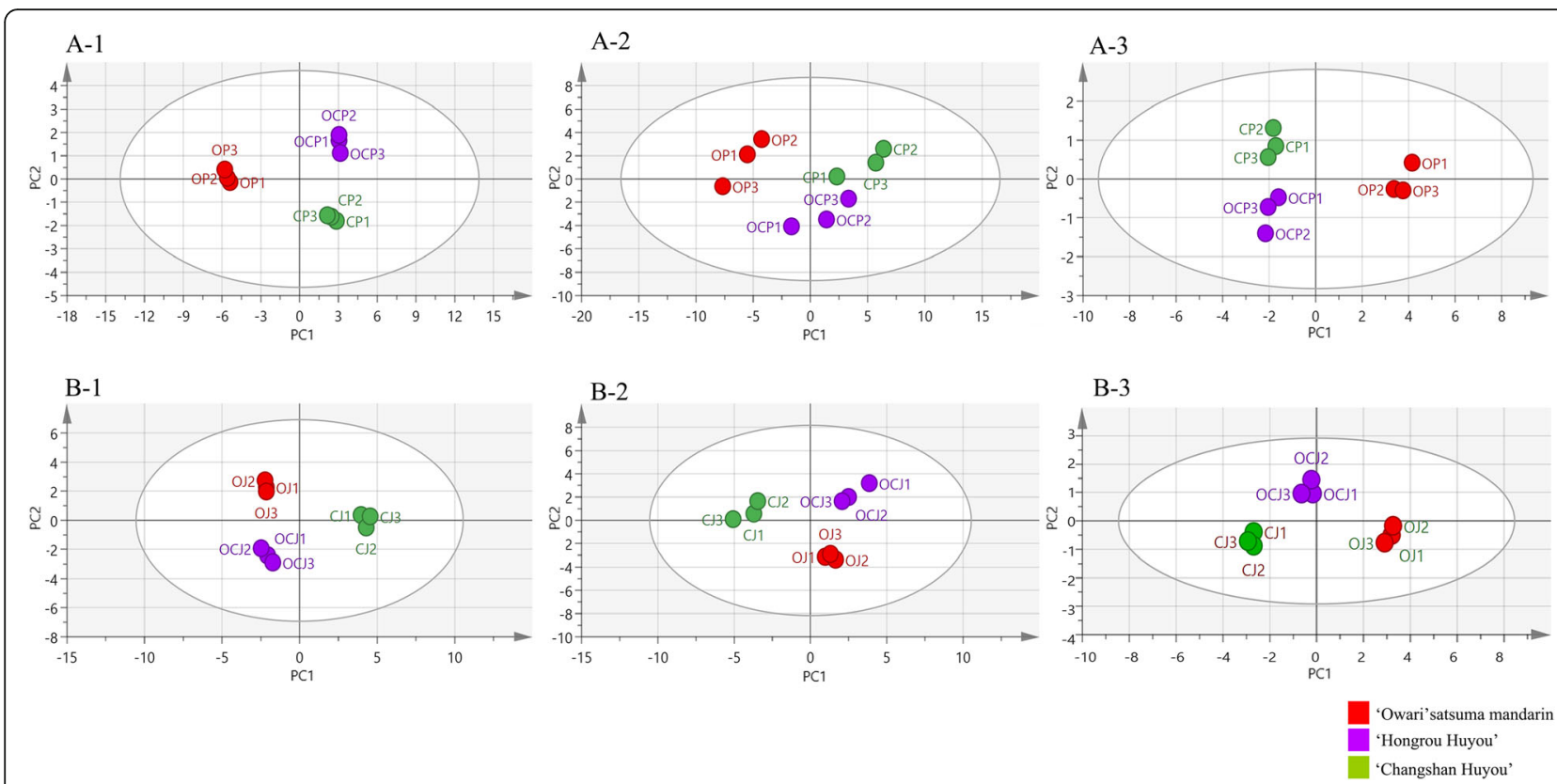

Fig. 2 Metabolite contents of the fruit tissues in OCC and its donor plants were analyzed by PCAPrimary metabolites (A-1), volatiles (A-2) and carotenoids (A-3) were analyzed in the peels of the three cultivars. Primary metabolites (B-1), volatiles (B-2) and carotenoids (B-3) were analyzed in the juice sacs of the three cultivars. The bold dots colored in red, purple, and green represent O, OCC and C, respectively.

\section{Characteristic metabolite analysis in OCC}

However, the accumulation of a number of metabolites (including primary metabolites and volatiles) in OCC were specific to the layer source donors; some metabolites deviated far from the profile observed in both donors (i.e., significantly higher or lower than both donors). This observation was similar to two citrus hybrids that exhibited 56 of the 113 volatile profiles in hybrids that were significantly higher or lower than in parents [34]. In this study, the content of germacrene D (Table 5) in OCJ was 6 and 17 times higher than that in $\mathrm{CJ}$ and OJ, respectively. The quantities of arabinose were over 3 and 9 times higher than those in CJ and OJ, respectively (Table 3), and this profile has been reported to be a good source of dietary fiber and could be available for juice production [35]. Taken together, the results suggested that the expression levels of genes were altered, possibly due to layer displacement.

Interestingly, a volatile named $\alpha$-ylangene was exclusively detected in the juice sac of the chimera OCC (Table 5). $\alpha$-ylangene is a unique compound that has been rarely reported in any citrus volatile profiles and is a main sesquiterpenoid at the postmaturation stage in grapes [36]. Similarly, a previous study reported that the citrus chimeras NFF and FNN had specific new bands, in addition to the specific bands of the two donor plants, as detected by RAPD analysis, suggesting that the chimeras interacted at the DNA level [2]. Therefore, it was speculated that genetic mutations involved in intercellular movement may be responsible for $\alpha$-ylangene synthesis exclusively in
OCC during the development of the chimera. Recently, genetic mutations were suggested to impact the translocation and biological activities of transcription factors (TFs) within a plant $[37,38]$. In addition, the heritable variations caused by intercellular trafficking and genetic mutations were extensively studied in chimeras. A grape periclinal chimera 'Malian' was derived from cell invasion into L2 to give rise to a spontaneous mutation with bronze flesh [39]. Some studies have reported that berry color variants in grape Pinot can be mapped back to a mutation on a single locus named the "berry color locus", which encodes four tandem $M Y B$ transcription factors on chromosome 2 [40-42]. Fernandez and his colleagues investigated the weight reduction in the berry of a grape chimera, which was caused by unusual $V v p I$ gene expression in L1, in L2 or in both cell layers, leading to phenotypic variation (fleshless) in progeny [43]. In a peach mutant, a mutated cell carried a PRUPE.6G281100 allele into L2, causing a change in phenotype from flat to round in peach [44].

\section{Speculation of genetic laws in the metabolites of chimeras}

To date, there is limited knowledge available regarding the inheritance pattern of chemical compounds in plant chimeras. The donor bias was a compelling issue in the artificial synthesis of chimeras and in plant breeding. Arguments on the relationship between the chimeric phenotype and the traits of grafting donors have been proposed. It seemed that the stock donor Satsuma mandarin likely acted as the inner layer (L1) donor, with a 
focus on carotenoid synthesis $[4,5,45]$. Therefore, several novel phenotypes with "red-flesh", including OCC in this study, were discovered after grafting. Coinciding with these reports, the coloration in the peel and juice sac of OCC was similar to that of the layer source donor; however, the compositions of primary metabolites (such as organic acids and sugars) and volatiles (such as $\gamma$-terpinene) were partly different from the layer donor and displayed possible "recombination" between layers. Recently, small RNAs and DNA methylation have been considered to be involved in stock-scion interactions to describe genetic variations in graft chimeras. For instance, researchers have found that some conserved miRNAs were differentially expressed in graft chimera (Brassica juncea $+B$. oleracea) progeny rTTT (sexual self-crossing of the chimera) and donor plant TTT ( $B$. juncea), which may contribute to the changes in the expression of their target genes [30]. Furthermore, in graft chimeras of Brassica juncea and B. oleracea, sequencing analysis revealed that DNA methylation affects flowering time- and gibberellin response-related gene expression and may lead to phenotypic variations in progenies [6]. Therefore, because OCC possessed metabolites more similar to one donor or an intermediate between both donors, delivery factors that modulate the genes involved in metabolite production, transport and accumulation may be impaired.

\section{Conclusions}

The gene expression pattern and accumulation of primary metabolites, volatiles and carotenoids derived from the peels and juice sacs of OCC and the two donors were systematically investigated and compared. The content and composition of metabolites were different among the genotypes and the tissues. Metabolites specifically present or absent in certain tissues ( $\alpha$-carotene and phytoene) were identified in three genotypes. A clear donor dominant pattern of metabolite inheritance was observed in the different tissues of OCC, indicating that the metabolites in the juice sacs of the chimera were similar to those from the $\mathrm{L} 1$ donor $\mathrm{O}$ and that those in the peels of the chimera were similar to the L2/L3 donor C. These profiles provide potential chemical markers for genotype differentiation and citrus breeding assessment; moreover, they provide information for donor selection during artificial chimera synthesis.

\section{Methods}

\section{Plant materials and sampling}

The OCC was generated by top-grafting of the scion $\mathrm{C}$ and the stock $\mathrm{O}$ in 2001, however, it was found recently in our bud mutation investigation in an orchard in Changshan County of Zhejiang Province (China). Recently, OCC was identified to be a grafting chimera in our analysis of the morphological and DNA characteristics of the chimera and the two donors (unpublished data). For commercial production, OCC and the donors ( $\mathrm{O}$ and $\mathrm{C}$ ) were separately grafted onto Poncirus trifoliata in 2005 and maintained stable morphologies for 12 years under regular management. Three individual trees were selected for each genotype, and 10 fruits with uniform size, peel color and location on the tree were harvested from each tree at the full ripening stage. Peels including the epidermis, flavedo and albedo were separated carefully and quickly from the juice sacs of each genotype by girdling. The peels and juice sacs obtained from one tree were separately blended and ground into powder in liquid nitrogen. Finally, the samples were preserved at $-80^{\circ} \mathrm{C}$ for subsequent research.

\section{Primary metabolites and volatile extraction}

The primary and volatile substances were evaluated using a modification of the procedure originally developed [46]. To determine the primary contents, we first ground $0.2 \mathrm{~g}$ of tissue into powder using liquid nitrogen and then added $2.7 \mathrm{ml}$ of pure, precooled $\left(-20^{\circ} \mathrm{C}\right)$ methanol. These components were mixed, and $0.3 \mathrm{ml}$ of ribitol $(0.2 \mathrm{~g} / \mathrm{ml})$ was added as an internal standards. The procedure was later applied to the volatile samples.

For volatile analysis, the samples were freeze-dried with a vacuum freeze-drier (Labconco FreeZoneR, USA) and fully ground in liquid nitrogen. A $0.2 \mathrm{~g}$ sample of powder was poured into a centrifuge tube ( $2 \mathrm{ml}$ volume), which was homogenized with $500 \mu$ l of double distilled water (DDW) and $500 \mu \mathrm{l}$ of MTBE (containing $0.02 \mu \mathrm{l} /$ $\mathrm{ml}$ methyl pelargonate), followed by gentle shaking. The samples were vibrated using an ultrasonic bath (model FS60, Fisher Scientific, Pittsburgh, PA) maintained at $4{ }^{\circ} \mathrm{C}$ for $40 \mathrm{~min}$ and were centrifuged at $12000 \times \mathrm{g}$ for 10 min at $4{ }^{\circ} \mathrm{C}$. The supernatants $(200 \mu \mathrm{l})$ were then transferred into another tube. Finally, $1 \mu \mathrm{l}$ of sample was injected with a syringe and filtered through a $0.22 \mu \mathrm{m}$ membrane (SCAA-104, ANPEL, Shanghai, China) for gas chromatography-mass spectrometry (GC-MS).

\section{Primary metabolite and volatile analysis}

The compounds were identified by using TRACE GC Ultra GC coupled with a DSQ II mass spectrometer (Thermo Fisher Scientific, Waltham, MA, USA) with a TRACE TR-5 MS column $(30 \mathrm{~m} \times 0.25 \mathrm{~mm} \times 0.25 \mu \mathrm{m}$; Thermo Scientific, Bellefonte, PA, USA). With pure helium as a carrier gas, the peels (flavedo and albedo) and juice sacs of the samples were assayed at $1.0 \mathrm{ml} / \mathrm{min}$ with a split ratio of 50:1 and 1:1, respectively. The concentrations of the primary and volatile substances were calculated as $\mu \mathrm{g} / \mathrm{g}$ FW. Three replications were used for each sample. 
The public databases Massbank (http://www.massbank.jp/) and Metlin (https://metlin.scripps.edu/index. pCF) supported the identification of tentative metabolite substances; for some other compounds, we obtained information from the published literature.

\section{Carotenoid extraction}

The total carotenoids in OCC and its donor parents were extracted according to a previously described method [47] with some modification. Juice sac powder $(1 \mathrm{~g})$ and peel powder $(0.5-1 \mathrm{~g})$ were homogenized in a $50 \mathrm{ml}$ centrifuge tube after lyophilization using a lyophilizer (LABCONCO FreeZone ${ }^{\circ}$ ). Next, $15 \mathrm{ml}$ of pigment extraction solvent (n-hexane/acetone/anhydrous ethanol, 2:1:1, v/v/v, containing 0.1\% BHT) was added. The samples were subjected to ultrasonic vibration for $30 \mathrm{~min}$ and centrifuged for $10 \mathrm{~min}$ at $4000 \times \mathrm{g}$ at $4{ }^{\circ} \mathrm{C}$. The supernatants were transferred to another $50 \mathrm{ml}$ centrifuge tube, and the sediment was extracted using $15 \mathrm{ml}$ pigment solvent until it was colorless. The supernatants were combined in a $50 \mathrm{ml}$ separating funnel and washed 3 times using a saturated $10 \% \mathrm{NaCl}$ solution until neutral, and the underlayer was discarded. Then, the supernatants were separated into a $10 \mathrm{ml}$ centrifuge tube and concentrated under vacuum conditions. The samples were redissolved with $2 \mathrm{ml}$ of methyl tert-butyl ether (MTBE) and $2 \mathrm{ml}$ of $10 \% \mathrm{KOH}$ (containing 0.1\% BHT), and the residue was dried under nitrogen. The samples were kept in the dark for $10 \mathrm{~h}$ for saponification. Then, $4 \mathrm{ml}$ of saturated $\mathrm{NaCl}$ and $2 \mathrm{ml}$ of MTBE (containing $0.1 \%$ BHT) were added to better separate the layers and to wash away the water, and $5 \mathrm{ml}$ of $\mathrm{NaCl}$ was added 3 times to wash the solution to neutral. Meanwhile, the supernatant was concentrated by vacuum and was diluted with $0.6-1 \mathrm{ml}$ of MTBE (containing $0.1 \%$ BHT). The samples were centrifuged at $12000 \mathrm{rpm}$ for $30 \mathrm{~min}$ at $4{ }^{\circ} \mathrm{C}$ for subsequent analysis.

\section{Carotenoid analysis}

A gradient elution method of OCPLC, composed of A (acetonitrile/methanol, 3:1, v/v, containing 0.1\% BHT, $0.05 \%$ TEA) and B (100\% MTBE, containing 0.1\% BHT) as the mobile phase, was used to determine the carotenoid contents. The flow rate was fixed at $1 \mathrm{ml} / \mathrm{min}$. The following gradients were used: $0 \mathrm{~min},(95: 5) ; 0-10 \mathrm{~min}$, A-B (95:5); 10-19 min, A-B (86:14); 19-29 min, A-B (75: 25); $29-54 \mathrm{~min}, \mathrm{~A}-\mathrm{B}(50: 50) ; 54-66 \mathrm{~min}, \mathrm{~A}-\mathrm{B}$ (26:74); and $67 \mathrm{~min}, \mathrm{~A}-\mathrm{B}$ (95:5). The volume of the above gradient solvent was $20 \mu \mathrm{l}$, and the test adopted an external standard method for quantitation. All carotenoid extraction, saponification and other assays described above were conducted under low light levels or in the dark.

\section{Statistical analysis}

The concentration of each chemical compound is shown as the mean \pm standard deviation of three replicates.
Statistical analysis was performed using SPSS 19.0 software (SPSS Inc., Chicago, IL, USA). Significant differences were calculated using one-way analysis of variance (ANOVA) followed by Duncan's multiple-range test at the 5\% level $(p<0.05)$ and are shown in the tables with lowercase letters (a, b, c, etc.) between cultivars. Undetectable substances are marked with "nd" in all metabolite profile tables. Correlation analysis was carried out by Pearson's test, and significant differences were marked with “*:*" $(p<0.01)$. Principal component analysis was carried out by SIMCA 14.1.

\section{Abbreviations \\ CJ: the juice sac of 'Changshan Huyou'; CP: the peel of 'Changshan Huyou'; OCJ: the juice sac of OCC; OCP: the peel of OCC; OJ: the juice sac of 'Owari' satsuma mandarin; OP: the peel of 'Owari' satsuma mandarin;}

\section{Acknowledgements}

Not applicable.

\section{Consent to publish}

Not applicable.

\section{Authors' contributions}

$M Z$ and $C Z$ designed this work and substantively revised the manuscript. $L J$ contributed to the data analysis and drafted the manuscript. QW contributed to the harvest of experimental materials. KZ performed the experiments. FK and JX contributed to maintenance management of the chimera plants and provided financial support. SZ and GW contributed to planting management of experimental materials. All authors read and approved the final manuscript.

\section{Funding}

This research was supported by the Public Projects of Zhejiang province (LGN18C160005, LGN19C160005); the National Natural Science Foundation of China (31000897, 31301811); the Science Technology Department of Zhejiang Province (No. 2016C02052-1); and the earmarked fund for the China Agriculture Research System (CARS-27). The funding bodies did not play any role in the design of the study and collection, analysis, and interpretation of data and in writing the manuscript.

Availability of data and materials

All data generated and analyzed in this study is presented in this published article.

Ethics approval and consent to participate

Not applicable.

\section{Competing interests}

The authors declare that they have no competing interests.

\section{Author details \\ ${ }^{1}$ State Key Laboratory of Subtropical Silviculture, Zhejiang A\& F University, Hangzhou 311300, China. ${ }^{2}$ Quzhou Technical Extension Station for Cash Crops, Quzhou 324000, China. ${ }^{3}$ Key Laboratory of Horticultural Plant Biology (Ministry of Education), Huazhong Agricultural University, Wuhan 430070, China. ${ }^{4}$ Citrus Research Institute of Zhejiang Province, Huangyan 318020, China. ${ }^{5}$ Changshan Huyou Research Institute, Quzhou 324000, China.}

Received: 23 May 2019 Accepted: 28 November 2019 Published online: 26 December 2019

\section{References}

1. Marcotrigiano M, Bernatzk R. Arrangement of cell layers in the shoot apical meristems of periclinal chimeras influences cell fate. Plant J. 1995;7(2):193-202.

2. Zhou JM, Hirata Y, Nou IS, Shiotani H, Ito T. Interactions between different genotypic tissues in citrus graft chimeras. Euphytica. 2002;126(3):355-64. 
3. Wu S, Li HY, Liang YR, Hirata Y. Morphological and genetic analysis on one combination of chimaeriferus citrus and its donor plants. J Fruit Sci. 2007;24(1):1-5.

4. Zhang $M$, Deng XX, Qin CP, Chen CL, Zhang HY, Liu Q, Hu ZY, Guo LL,Song WH,Tan Y,Liao SC. Characterization of a new natural periclinal navelSatsuma chimera of Citrus: 'Zaohong' navel orange. J Am Soc Hortic Sci. 2007;132(3):1545-50.

5. Zhang M, Xie ZZ, Deng XX, Liao SC, Song WH, Tan Y. Characteristics of 'Hongrou Taoye', a grafted chimera in sweet orange and Satsuma mandarin. Kor J Hort Sci Technol. 2015;33(3):390-5.

6. Li SJ, Wang Z, Ding F, Sun D, Ma ZC, Cheng YJ, Xu J. Content changes of bitter compounds in 'Guoqing no.1' Satsuma mandarin (Citrus unshiu Marc.) during fruit development of consecutive 3 seasons. Food Chem. 2014; 145(13):963-9.

7. Jing L, Lei ZT, Zhang GW, Alan CP, David VH, Xie JR, Xi WP, Zhou ZQ, Sumner LW. Metabolite profiles of essential oils in citrus peels and their taxonomic implications. Metabolomics. 2015;11(4):952-63.

8. Zhang HP, Xie YX, Liu CH, Chen SL, Hu SS, Xie ZZ, Deng XX, Xu J. Comprehensive comparative analysis of volatile compounds in citrus fruits of different species. Food Chem. 2017;230:316-26.

9. Shao QS, Liu HB, Zhang AL, Wan YY, Hu RH, Li MY. Analysis of volatile components extracted from the peels of four different Chinese pommelos using TDS-GC-MS. J Sci Food Agric. 2015;94(15):3248-54.

10. Chappell J. The biochemistry and molecular biology of isoprenoid metabolism. Plant Physiol. 1995;107(1):1-6.

11. Pan ZY, Liu Q, Yun Z, Guan R, Zeng WF, Xu Q, Deng XX. Comparative proteomics of a lycopene-accumulating mutant reveals the important role of oxidative stress on carotenogenesis in sweet orange (Citrus sinensis [L.] Osbeck). Proteomics. 2009;9(24):5455-70.

12. Vigushin DM, Poon GK, Boddy A, English J, Halbert GW, Pagonis C, et al. Phase I and pharmacokinetic study of $d$-limonene in patients with advanced cancer. Cancer Chemother Pharmacol. 1998;42(2):111-7.

13. Peana AT, D'Aquila PS, Panin F, Serra G, Pippia P, Moretti MD. Antiinflammatory activity of linalool and linalyl acetate constituents of essential oils. Phytomedicine. 2002;9(8):721-6.

14. Nils B, Konig WA. The role of germacrene D as a precursor in sesquiterpene biosynthesis: investigations of acid catalyzed, photochemically and thermally induced rearrangements. Phytochemistry. 2000;55(2):141-68.

15. Ikoma $Y$, Matsumoto $H$, Kato M. Diversity in the carotenoid profiles and the expression of genes related to carotenoid accumulation among citrus genotypes. Breed Sci. 2016;66:139-47.

16. Goodner KL, Rouseff RL, Hofsommer OCJ. Orange, mandarin, and hybrid classification using multivariate statistics based on carotenoid profiles. J Agric Food Chem. 2001;49(3):1146-50.

17. Kato $M$, Ikoma $Y$, Matsumoto $H$, Sugiura $M$, Hyodo $H$, Yano M. Accumulation of carotenoids and expression of carotenoid biosynthetic genes during maturation in citrus fruit. Plant Physiol. 2004;134(2):824-37.

18. Alquezar B, Rodrigo MJ, Zacarías L. Carotenoid biosynthesis and their regulation in citrus fruits. Tree For Sci Biotechnol. 2008a;2(1):23-5.

19. Alquezar B, Rodrigo MJ, Zacarías L. Regulation of carotenoid biosynthesis during fruit maturation in the red-fleshed orange mutant Cara Cara. Phytochemistry. 2008b;69(10):1997-2007.

20. Winkler H. Über Pfropfbastarde und pflflanliche Chimären. Ber Der Dtsch Bot Ges. 1907;25:568-76.

21. Neilson-Jones W. Plant chimeras. London: Methuen; 1969

22. Stewart RN, Meyer FG, Dermen H. Camellia+'Daisy Eagleson', a graft chimera of Camellia sasanqua and C. japonia. Am J Bot. 1972;59:515-24.

23. Jwamasa MNM, Okudal N, Ishiuchi D. in International Citrus Congress, Florida, USA, 71-574 (FL, 1977).

24. Gross J. Carotenoids: pigments in fruits. London: Academic; 1987

25. Fanciullino AL, Dhuique-Mayer C, Luro F, Casanova J, Morillon R, Ollitrault P. Carotenoid diversity in cultivated citrus is highly influenced by genetic factors. J Agric Food Chem. 2006;54:4397-406.

26. Matsumoto $H$, Ikoma $Y$, Kato $M$, Kuniga T, Nakajima N, Yoshida $T$. Quantification of carotenoids in citrus fruit by LC-MS and comparison of patterns of seasonal changes for carotenoids among citrus varieties. J Agric Food Chem. 2007;55:2356-68.

27. Wang JR. A new citrus variety: 'Golden pummelo'. Zhejiang Citrus. 1991;1:5-7.

28. Chen LG, Hu XQ, Zhao SQ. Molecular research on Huyou origin. Hortic Plant J. 2002;29(3):276-7.
29. Chen SC, Yang H, Zheng YP, Chen YL, Qiu YX. Preliminary identification of Citrus changshanhuyou elite genotypes by molecular markers. J Mol Cell Biol. 2007;39(6):502-8.

30. Li JX, Wang Y, Zhang LL, Liu B, Cao LW, Qi ZY, Chen LP. Heritable variation and small RNAs in the progeny of chimeras of Brassica juncea and Brassica oleracea. J Exp Bot. 2013;64(16):4851-62.

31. Bassene JB, Froelicher Y, Dhuique-Mayer C, Mouhaya W, Ferrer RM, Ancillo G, Morillon R, Navarro L, Ollitrault P. Non-additive phenotypic and transcriptomic inheritance in a citrus allotetraploid somatic hybrid between C. reticulata and C. limon: the case of pulp carotenoid biosynthesis pathway. Plant Cell Rep. 2009;28(11):1689-97.

32. Zheng BB, Xie ZZ, Guo WW. Parental dominant inheritance of fruit carotenoids, sugars and organic acids in a citrus interspecific allotetraploid somatic hybrid between Bonnaza navel Orange and rough lemon. Acta Hortic Sin. 2013;40(7):1262-8.

33. Cao LW, Yu NN, Li JX, Qi ZY, Wang D, Chen LP. Heritability and reversibility of DNA methylation induced by in vitro grafting between Brassica juncea and B. oleracea. Sci Rep. 2016;6(1):27233.

34. Rambla JL, Gonzálezmas MC, Pons C, Bernet GP, Asins MJ, Granell A. Fruit volatile profiles of two citrus hybrids are dramatically different from those of their parents. J Agric Food Chem. 2014;62(46):11312-22.

35. Wang L, Xu HG, Yuan F, Pan QY, Fan R, Gao YX. Physicochemical characterization of five types of citrus dietary fibers. Biocatal Agric Biotechnol. 2015;4(2):250-8.

36. Coelho E, Silvia MR, Delgadillo I, Coimbra MA. Headspace-SPME applied to varietal volatile components evolution during Vitis vinifera L. Cv. 'Baga' ripening. Anal Chim Acta. 2006;563(1):204-14.

37. Mezitt LA, Lucas WJ. Plasmodesmal cell-to-cell transport of proteins and nucleic acids. Plant Mol Biol. 1996;32(1-2):251-73.

38. Sessions A. Cell-cell signaling and movement by the floral transcription factors Leafy and Apetala1. Science. 2000;289(5480):779-81.

39. Walker AR, Lee E, Robinson SP. Two new grape cultivars, bud sports of cabernet sauvignon bearing pale-coloured berries, are the result of deletion of two regulatory genes of the berry colour locus. Plant Mol Biol. 2006;62(4-5):623-35.

40. Migliaro D, Crespan M, Muñoz-Organero G, Velasco R, Moser C, Vezzulli S. Structural dynamics at the berry colour locus in Vitis vinifera L. somatic variants. Aust J Grape Wine R. 2015;20(3):485-95.

41. Silvia V, Lorena L, Umberto M, Marco S, Riccardo V, Claudio M. Pinot blanc and pinot gris arose as independent somatic mutations of pinot noir. J Exp Bot. 2012;63(18):6359-69.

42. Azuma A, Udo Y, Sato A, Mitani N, Kuno A, Ban Y, Yakushiji H, Koshita Y, Kobayashi S. Haplotype composition at the color locus is a major genetic determinant of skin color variation in vitis xlabruscana grapes. Theor Appl Genet. 2011;122(7):1427-38.

43. Fernandez L, Doligez A, Lopez G, Thomas MR, Bouquet A, Torregrosa L. Somatic chimerism, genetic inheritance, and mapping of the fleshless berry (flb) mutation in grapevine (Vitis vinifera L). Genome. 2006;49(7):721-8.

44. López-Girona E, Zhang Y, Eduardo I, Jrh M, Alexiou KG, Arús P, Aranzana MJ. A deletion affecting an LRR-RLK gene co-segregates with the fruit flat shape trait in peach. Sci Rep. 2017;7(1):6714-25.

45. Wu JX, Xiao HL, XH W, Yi HL. Identification of fruit cell source of graft chimera 'Zaohong' navel orange and analysis of soluble sugars,organic acids and aromas of fruit. Acta Hortic Sin. 2014;41(10):1993-2000.

46. Liu CH, Cheng YJ, Zhang HY, Deng XX, Chen F, Xu J. Volatile constituents of wild Citrus Mangshanyegan (Citrus nobilis Lauriro) peel oil. J Agric Food Chem. 2012;60(10):2617-28.

47. Jayaraj J, Devlin R, Punja Z. Metabolic engineering of novel ketocarotenoid production in carrot plants. Transgenic Res. 2008;17(4):489-501.

\section{Publisher's Note}

Springer Nature remains neutral with regard to jurisdictional claims in published maps and institutional affiliations. 